\title{
The Construction of the Model for the Prediction of Teachers' Professional Titles in Open University
}

\author{
Yue Ying \\ Department of Personnel, Zhejiang Radio and Television University, Hangzhou, China \\ Email: 88822392@163.com
}

How to cite this paper: Ying, Y. (2017) The Construction of the Model for the Prediction of Teachers' Professional Titles in Open University. Open Access Library Journal, 4: e3508.

https://doi.org/10.4236/oalib.1103508

Received: March 9, 2017

Accepted: May 2, 2017

Published: May 5, 2017

Copyright $\odot 2017$ by author and Open Access Library Inc.

This work is licensed under the Creative Commons Attribution International License (CC BY 4.0).

http://creativecommons.org/licenses/by/4.0/

\section{c) (i) Open Access}

\begin{abstract}
The title system of colleges and universities is closely related to the vital interests of teachers, the construction of teaching staff and the development of higher education. However, in the implementation process, there are still many problems, such as the complexity of post classification, the subjective factors of evaluation and employment, and so on. Therefore, it is necessary to implement the central authorities to deepen the reform of personnel system, deepen the reform of the title system and the spirit of the requirements. The construction of open university teachers professional title evaluation model is to solve the problem of the construction of open universities, which can predict the development trend of talents, the formation of talent development planning guidance and institutional guarantee measures clearly, to better serve the professional growth of teachers, and to promote the reform and development of open university education further.
\end{abstract}

\section{Subject Areas}

Education

\section{Keywords}

Open University, Professional Title, Teaching Staff, Prediction Model

\section{1. 引言}

职称是用人单位根据实际工作需要而设置的, 有明确岗位职责、任职条 件及任期, 并需要具备专业的业务知识和技术水平才能担任的工作岗位 [1]。 与一次获得后而终身拥有的学位、学衔等各种学术、技术称号相区别, 职称 评审通过对专业技术人才的测定、品评和区分, 具有以下两种功能：其一, 对专业技术人才所具有的能力水准进行衡量和识别(信息功能); 其二, 为专业 
技术人才评聘提供一种能力资格的判断和评价依据(管理功能) [2]。职称评定 对个人发展的重要性不言而喻, 它是对人才资源进行评价使用的重要手段, 也是人事人才工作的一个重要组成部分。它在人才的使用、流动、培养、选 拔, 以及人才资源开发各个环节中, 都发挥着突出的作用。在当今社会, 在 能力重于学历、水平重于文凭的共识下, 职称制度体现出的竞争机制, 对个 人的能力发展具有积极的导向作用、评价作用和激励作用, 同时对社会生产 和管理具有巨大的促进作用。

师资队伍是高等学校提高办学水平、增强服务能力的第一资源, 高校品 牌的树立、社会的认同、学生的认可与学校师资队伍建设密切相关。高校教 师职称评审是对教师科研水平、教学业绩和工作能力等的综合性评价。作为 一种学术资源的分配方式和用人评价机制, 职称评审在高校师资队伍建设中 正起着越来越重要的作用。

教师职务评聘政策研究是高等院校管理研究的重要组成部分, 自 1986 年 实行聘任制改革以来, 评聘政策及实践发生的深刻变化都体现在相关政策研 究中。在 1985 年中共中央印发的《中共中央关于教育体制改革的决定》中, 明确提出了 “改变政府对高等学校统得过多的管理体制......扩大高等学校的 办学自主权” [3]。1986 2013 年间, 国家各部委先后出台了 84 个高校人事制 度改革的文件, 其中 14 个文件与教师职务评聘直接相关。其他有关高等教育 的法律法规、分配制度和综合改革的文件, 也从多方面各层次深化了聘任制 改革。在人事部事业单位岗位设置的推动下, 自 2001 年开始, 高校进入聘任 制全面落实阶段, 职称制度逐步从评聘制逐步向聘任制渐进式推进。

多年来, 职称评价制度对专业技术人才的成长起到了很大的推动作用。 但同时, 人才评用脱节一直是职称评价制度中的弊端。主因是由于政府职能 主管部门负责职称评审工作, 而高校和科研院所等用人单位缺乏自主权, 造 成了 “用的评不上, 评的用不上”。为改变这种状况, 进一步加强高校师资 队伍建设, 更好地发挥职称评审工作的激励导向作用, 推动高校科学发展、 特色发展、和谐发展, 必须深入探索建立高校自主评聘、政府宏观管理监督 的高校教师职称评聘制度。

根据中央全面深化改革的指导思想, 自 2014 年起, 浙江省不再统一组织 全省高校教师高级职称资格评审工作, 而改由各高校自主开展教师职称评聘 工作, 自定标准, 自主评聘, 自主发证。2016 年 3 月, 中央通过了《关于深 化人才发展体制机制改革的意见》，其对我国现有的人才发展的体制、机制 均提出了重大的改革意见: 要创新当前的人才评价机制, 优化人才评价的 “指 挥棒” 作用; 通过深化职称制度改革, 突出用人主体在职称评审中的主导作 用, 合理界定和下放职称评审权限, 不断推动高校及科研院所的自主评审权, 提高职称评审的科学化水平 [4]。聘任制的推进, 意味着将聘任制进一步深化, 政府主要通过角色调控和宏观规划的方式来调整岗位比例和结构, 实现宏观 动态管理; 高校在享有较大办学自主权的前提下, 实施岗位聘任, 不但可以 有效实现学校自主用人、教师自主选择岗位、政府依法监督的用人机制, 还 能形成有序竞争、包容开放的人事机制。岗位聘任工作得以实现规范化、科 学化、制度化, 从而使教师的根本利益和学校的基本权利得到实实在在的维 
护和保障[4]。从实际效果来看, 这些改革举措大大增强了高校教师队伍建设 的自主权, 浙江省各高校纷纷根据学校自身发展需要, 结合学科专业特点, 制定符合学校实际、针对性更强的教师职称评审标准体系。

2016 年 6 月, 中共浙江省委浙江省人民政府印发了《关于深化人才发展 体制机制改革支持人才创业创新的意见》(浙委发(2016)14 号) [5], 提出 “将 专利创造、标准制订及成果转化作为职称评审的重要依据, 将发明专利转化 应用情况与论文指标要求同等对待, 横向课题与纵向课题指标同等对待。将 企业工作经历和工作业绩作为高校工程类教师晋升专业技术职务的重要条 件。业绩突出的优秀工程技术人员，可以破格或越级申报专业技术职称”。

继而在 2016 年 11 月, 中央全面深化改革领导小组通过了《关于深化职 称制度改革的意见》[6], 提出要以职业分类为基础, 以科学评价为核心, 以 促进人才开发使用为目的, 健全职称制度体系, 完善职称评价标准, 创新职 称评价机制, 促进职称评价和人才培养使用相结合, 改进职称管理服务方式; 改变以往 “唯学历、唯资历、唯论文” 的导向, 转而重视品德、业绩和能力; 一改以往注重身份、资格的弊端, 评审以考核、岗位、聘任为重。对人才的 评定标准做了更科学有效的规范。

职称制度的深化改革直指过往积弊, 并确立了一个正确的导向, 使人才 的评价标准更为多元, 破除 “一刀切” , 不搞一把尺子量到底的评价方法。 学历、论文兼顾能力、业绩, 在总体上力图实现社会公正评价、单位自主聘 任、政府宏观调控的人才评价与使用的改革目标。

广播电视大学全方位致力于向开放大学的转型升级, 以制度创新为起点, 加强开放大学的能力再造, 离不开一支规模宏大、结构合理、高素质的专业 技术人才队伍, 而专业技术人才量的聚集、质的扩张, 则需要切实可行的评 价激励机制以及合理的人力发展制度作为支撑的引擎动力。当前, 以评聘制 为主题的研究大多针对普通高等学校, 直面改革具体问题的政策手段调整, 围绕 “岗位设置”、“评聘模式”、“评审办法”、“评审标准” 等维度开 展研究, 通过分析梳理评聘制的发展轨迹, 指出当前评聘政策实践的困难与 应对, 结合具体问题研究评聘政策实施的可行性方案和合理化建议。其中, 职称评审模式设计和标准制定是量化评审模式的核心, 也是研究开展的难点 和热点。从当前的成果看, 现有研究着力突出高等教育系统内部不同层次类 型院校之间的分类特征, 结合区位学校建设发展目标, 建立符合自身实际发 展的科学评价体系, 注重实践的落地性和可操作性。如, 赵晓芳基于胜任力 要素构建了高职教师职称评定体系应包括多维立体的过程性评价体系和全方 位点面结合的评价内容体系[7]。郑柏松提出了系统论视角下符合高职教育特 点的教师职称评审体系的构建路径[8]。刘玉斌设计了专业技术职称评审模型 [9]。安璐提出了基于 BP 和 GRNN 模型的高校教师职称评审预测模型 [10]。 但这些研究中仍存在量化评定标准缺乏分析, 评价随意性较大, 科学性、系 统性不足的现象, 而利用广播电视大学系统的信息化优势, 借助于数据系统 分析技术, 可以弥补这一现象, 并且也填补了涉及广播电视大学及开放大学 职称制度的研究缺位。因此, 本研拟从广播电视大学的转型发展及开放大学 系统建设的发展定位和需求出发, 增强量化概念, 采用数据统计方法以及多 
种管理统计软件工具, 对职称的相关评价要素通过统计分析加以科学提炼归 纳, 从 “量化” 再到 “质量结合” 不断分类考量, 注重数据的形成性分析, 建立数据化、具有测评和预判性的职称评审体系。探索符合开放大学系统特 色, 并相对较为完备的教师职称评审指标体系, 着力打造开放大学人才发展 机制, 实现人才的生态性发展。

\section{2. 职称评审指标体系设计}

随着学习型社会建设和终身教育服务需求的提升, 广播电视大学正面临 转型浪潮, 内涵建设从来没有像今天这样重要 [11], 师资队伍的建设无疑成为 了内涵建设中最为关键的任务之一。开放大学建设与转型的关键在于, 开放 大学作为新型大学实体的综合办学和教学能力得到明显提升和充分显现。尤 其是其人才培养质量得到比较广泛的认可, 这些都需要不断提升电大系统师 资队伍建设水平, 提升教师素质, 树立开放大学教师品牌与形象。

2016 年 2 月, 教育部印发《关于办好开放大学的意见》, 提出要围绕课 程建设和学生自主学习, 加快建成一支适应开放教育特点、擅长运用信息技 术教学的专兼职结合的教师队伍。教师能力方面, 突出要求要在课程设计、 资源开发、软件开发、学习咨询、教学组织、学习引导等方面形成特色, 并 以课程设计为核心、以网络教学为重点、以服务学生为目标, 分别组建课程 建设团队、课程教学团队和课程辅导团队; 也要配备助学咨询教师和专业学 习辅导教师, 提供选课指导、制订个性化学习计划、学习方法引导、学业咨 询与提醒、学习资源获取、心理咨询、职业生涯规划等服务, 以及为学习者 提供在线辅导和答疑[12]。

浙江广播电视大学目前教师总数为 2874 人(含市县电大), 其中男性为 1450 人, 女性为 1424 人, 男女比例相对均衡。在教师当中, 超过 $85 \%$ 具有 中级及以上职称, 约 $30 \%$ 具有硕士或博士学位, 中高级职称比例相对合理, 但是高级职称教师特别是正高级职称教师偏少, 硕士或博士学位人员比例也 不高(图 1)。

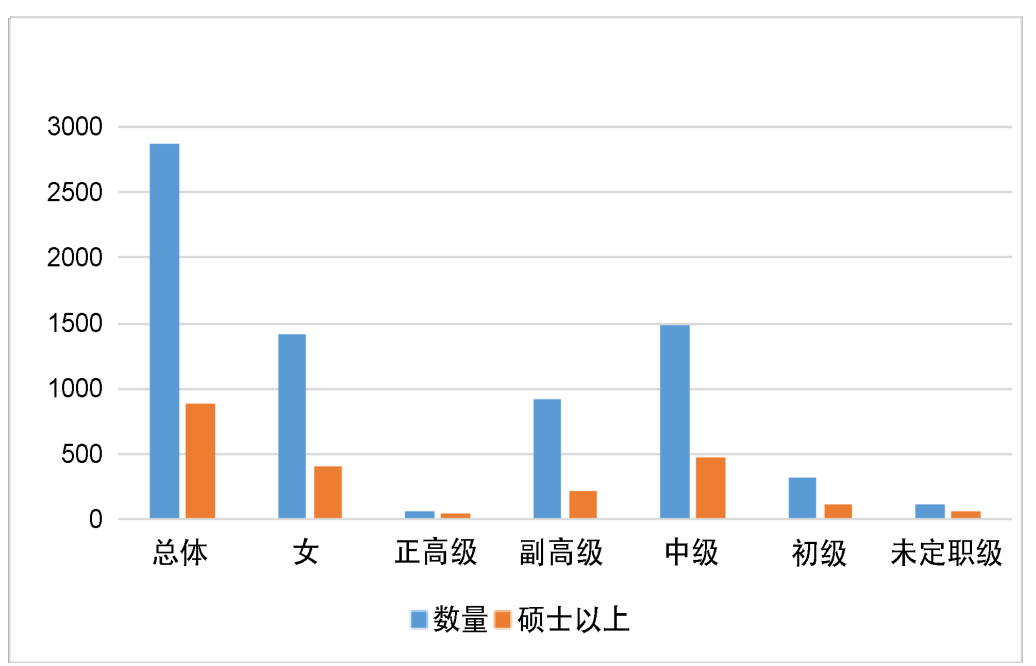

图 1. 浙江广播电视大学教师职称结构图。(注: 本数据来源于浙江广播电视 大学人事处) 


\section{(一) 职称评审指标体系建设}

自 2014 年起, 浙江广播电视大学开展了教师职称自主评聘工作。根据中 央和省深化职称制度改革精神, 教育部关于办好开放大学的意见, 以及全省 电大系统教师现状, 浙江广播电视大学在职称评审工作中坚持以下四点导向, 即: 有利于学校办学定位和科学发展, 有利于提高教师队伍整体素质和综合 实力, 有利于优化教师队伍结构, 有利于提高教学科研水平、人才培养质量 和社会服务能力, 既实现教师专业化发展, 又促进学校办学目标的实现。职 称评审指标评估模式采用制度主义的分析框架,通过对职称量化制度各级别 评审条件的量化结构设计, 优化方案、细化原则、完善制度, 可以更好地适 应师资队伍建设要求，动态灵活地反映教师专业技术发展情况，同时削弱人 为因素干扰, 突出公平性[13]。评审指标体系结合职称预测模型可以对教师职 称评审起到引导作用, 明确在职称评审过程中的努力方向, 起到更好的激励 效果, 对教师业绩起到正向的推动作用。

在高等院校中影响职称评聘的主要因素是科研水平与教学能力。评价指 标体系要广泛应用模糊综合评价法、多层次分析法、加权调整等方法, 建立 综合的评价模型[14]。浙江广播电视大学高级专业技术职务评审指标体系的建 设, 是基于电大转型定位及未来几年的人才队伍建设整体规划基础上设定的。 按照人才培养规律, 在近几年的评审过程中, 各项指标的标准不断提高, 但 直于样本数据的观察时间较短, 目前尚不足以形成明确的权重比例。具体如 表 1 所示。

（二）评审指标体系权重比例配置

评审指标体系覆盖面比较广, 这也是基于公平性的考虑。教师在专业技 术实际工作过程中, 研究方向与工作重点都有很大的区别, 指标的设计尽可 能地考虑到教师的全面发展与定位, 从学校定位、教师发展、人才培养等多 方面考虑设定评审指标项目。同时结合问卷调查，以及近几年的评审数据不 断调整各项目的权重比例。比如, 可以通过最新的评审结果运用统计分析法, 反推验证评审指标体系的科学性和合理性。

代表作鉴定是鉴定专家对申报者所提交的代表其本人水平的论文或著作 进行鉴定, 是对其内容所反映的专业与学术水平的鉴定, 更是对文章作者专 业能力与研究水平的认定 [15]。鉴定专家需要就申报者是否已达到所申报专业 技术职务相适应的水平, 作出结论。在指标体系中, 评审代表作的权重相对 较高。这也是基于评审代表作的特点, 以及评审结果分析得出来的。但是鉴 于该项指标受人为影响较大, 也特别关注到了量化测评制度体系内部产生的 结构失衡现象 $[16]$ 。

\section{3. 评审预测模型建构与数据分析}

\section{(一) 模型数据源}

本预测模型的数据来源选自浙江广播电视大学系统 2014、2015 两年全部 参评教职工职称评审数据, 共计 99 条记录。由于申报系列不同, 评审要求也 略有不同。为了得到更精准的分析结果, 选择申报系列为 “教师” 的高级职 称人员, 共计 73 条记录进行分析建模。 
表 1. 浙江广播电视大学专业技术职务评审指标体系(部分)

\begin{tabular}{|c|c|c|}
\hline 一级指标 & 二级指标 & 三级指标 \\
\hline \multirow{2}{*}{ 基本要求 } & 最高学历 & 本科以上 \\
\hline & 最高学位(年龄在 50 岁以上的无要求) & 硕士以上 \\
\hline \multirow{7}{*}{ 科研课题 } & \multirow{2}{*}{ 国家级课题 } & 排名第一(a1) \\
\hline & & 排名第二至第五(a2) \\
\hline & \multirow{2}{*}{ 省部级课题 } & 排名第一(a1) \\
\hline & & 排名第二至第三(a2) \\
\hline & \multicolumn{2}{|l|}{ 市厅级课题 } \\
\hline & \multirow{2}{*}{ 校级课题 } & 中央电大(国开)课题主持 \\
\hline & & 浙江电大课题主持 \\
\hline \multirow{6}{*}{ 论文发表 } & \multirow{2}{*}{ 国家一级刊物 } & 排名第一 \\
\hline & & 排名第二 \\
\hline & \multirow{2}{*}{ 国内其它核心期刊(CSSCI、浙大核心、北大核心) } & 排名第一 \\
\hline & & 排名第二 \\
\hline & \multirow{2}{*}{ 国外期刊 } & 排名第一 \\
\hline & & 排名第二 \\
\hline \multirow{6}{*}{ 科研成果奖项 } & 国家级 & \\
\hline & 省部级 & 排名第一 \\
\hline & \multirow{3}{*}{ 市厅级 } & 排名第二到第五 \\
\hline & & 排名第一 \\
\hline & & 排名第二 \\
\hline & 校级奖励 & \\
\hline \multicolumn{3}{|l|}{ 人才项目奖励 } \\
\hline \multirow{2}{*}{ 社会服务 } & 社会职务兼职 & \\
\hline & 社会服务 & \\
\hline \multirow{8}{*}{ 代表作 } & \multirow{4}{*}{ 第一篇代表作 } & 审核结果为 $\mathrm{A}$ \\
\hline & & 审核结果为 B \\
\hline & & 审核结果为 $\mathrm{C}$ \\
\hline & & 审核结果为 $\mathrm{D}$ \\
\hline & \multirow{4}{*}{ 第二篇代表作 } & 审核结果为 $\mathrm{A}$ \\
\hline & & 审核结果为 B \\
\hline & & 审核结果为 $\mathrm{C}$ \\
\hline & & 审核结果为 $\mathrm{D}$ \\
\hline
\end{tabular}

高级职称申报数据源中，教师的基本属性主要包括申报类型、教师类型、 学历、学位、岗位类别等, 其中学位为硕士的有 52 人, 点 $71.2 \%$ 。教师职称 按岗位职责和工作特点分为教学为主型、教学科研并重型、社会服务与推广 型等三个类型。申报者以前两个类型为主, 共 69 人, 占 $95 \%$; 申报社会服务 与推广型仅 4 人, 占 $5 \%$, 如表 2 所示。从分析结果发现, 部分基本属性也不 
表 2. 职称评审数据源结构(部分)

\begin{tabular}{|c|c|c|c|c|c|c|c|c|c|c|}
\hline $\begin{array}{l}\text { 申报 } \\
\text { 类型 }\end{array}$ & 最高学历 & $\begin{array}{l}\text { 最高 } \\
\text { 学位 }\end{array}$ & $\begin{array}{l}\text { 岗位 } \\
\text { 类别 }\end{array}$ & $\begin{array}{c}\text { 近三年年度 } \\
\text { 考核优秀次 } \\
\text { 数 }\end{array}$ & $\begin{array}{l}\text { 近五年教学业 } \\
\text { 绩为 A 个数 }\end{array}$ & $\begin{array}{l}\text { 论文总数 } \\
\text { (第一作者) }\end{array}$ & $\begin{array}{c}\text { 外文期刊 } \\
\text { 论文数 } \\
\text { (第一作者) }\end{array}$ & $\begin{array}{l}\text { 核心论文数 } \\
\text { (第一作者) }\end{array}$ & $\begin{array}{c}\text { 一级论文或著作 } \\
\text { 出版社数 } \\
\text { (第一作者) }\end{array}$ & $\begin{array}{l}\text { 项目 } \\
\text { 课题 } \\
\text { 总数 }\end{array}$ \\
\hline 晋升 & 教学为主型 硕士研究生 & 硕士 & 教学 & 2 & 3 & 3 & 0 & 0 & 0 & 5 \\
\hline 晋升 & 教学科研并重型硕士研究生 & 硕士 & 教学 & 1 & 1 & 4 & 0 & 2 & 0 & 5 \\
\hline 晋升 & 教学为主型 博士研究生 & 博士 & 教学 & 2 & 1 & 4 & 0 & 2 & 0 & 5 \\
\hline 晋升 & 教学科研并重型 大学本科 & 硕士 & 教学 & 0 & 3 & 4 & 0 & 3 & 1 & 5 \\
\hline 晋升 & 教学为主型 大学本科 & 硕士 & 教学 & 3 & 3 & 4 & 0 & 2 & 0 & 5 \\
\hline 转聘 & 教学科研并重型硕士研究生 & 硕士 & 教学 & 0 & 0 & 3 & 2 & 0 & 0 & 3 \\
\hline 晋升 & 教学科研并重型 大学本科 & 硕士 & 教学 & 1 & 2 & 4 & 0 & 3 & 0 & 5 \\
\hline 晋升 & 教学为主型 硕士研究生 & 硕士 & 教学 & 2 & 3 & 4 & 0 & 4 & 0 & 5 \\
\hline 晋升 & 教学科研并重型 大学本科 & 硕士 & 教学 & 3 & 5 & 4 & 1 & 3 & 0 & 5 \\
\hline
\end{tabular}

同程度地影响评审结果, 尤其是学位。目前, 职称的晋升并未对学历学位作 硬性规定。但在今后的评审中, 部分基本属性如学位也逐步会列入申报审核 的基本要求中。

本研究中的模型构建工具选用 SPSS Modeler 14, 该软件是一个业界领先 的数据挖掘平台, 拥有直观的可视化操作界面、自动化的数据准备和成熟的 预测分析模型。与前面几个版本相比, SPSS Modeler 14 在数据可视化和算法 可视化方面都作了改进和完善, 更有利于数据探索和模型的优化。尤其在决 策树和神经网络的计算方面都有所加强, 神经网络节点和决策树中的 C\&R 树、QUEST 和 CHAID 节点都得到明显增强并支持推进 bagging 技术。

\section{(二) 数据预处理}

表 2 显示的数据源是在原始数据基础上经过预处理的。数据预处理是数 据分析和模型建构的基础, 也是直接导致分析结果与模型质量的关键。根据 数据源的特点, 在对数据进行分析和模型建构之前, 主要对原数据进行数据 咒余处理、数据清洗、变量类型转换和自变量选择等操作。

数据冗余处理: 部分字段之间有明显的同类性, 造成分析过程中的数据 咒余, 影响分析结果。如代表作鉴定 1 和代表作鉴定 2, 明显属于同一类因 子, 可通过将两项叠加后合并成一项并去除原数据。

变量类型转换: 原数据中, 部分字段是分类变量, 不利于实际分析。需 要转换成连续型变量。例如, 代表作原来是分为 $\mathrm{A} 、 \mathrm{~B} 、 \mathrm{C} 、 \mathrm{D}$ 四个等级, 可 以通过将等级分值化处理, 设定 $\mathrm{A}$ 为 4 分, $\mathrm{B}$ 为 3 分, $\mathrm{C}$ 为 2 分, $\mathrm{D}$ 为 1 分, 则两项代表作皆为 $\mathrm{A}$ 的即得 8 分。

数据清洗: 部分数列由于当前定位较高, 暂时缺乏实效数据或实效数据 比例过低, 没有分析意义的不列入统计范围, 如省部级奖励人才项目育人成 果数、国家级奖励人才项目育人成果数、国家级课题项目数等数据量缺失或 过少的都不列入统计范围。

自变量选择: 考虑到在今后的职称评审过程中, 要求会不断提升, 整体 指标体系的设定要求需要具备一定的可持续性和高标准性。目前, 部分指标 暂不列为统计自变量。在选择变量时, 先做分箱处理, 并做了主成份分析和 
因子分析。在此基础上结合数据的分布性, 选取了下列字段作为建模和分析 的输入自变量, 主要包括申代表作评审、申报类型、项目课题总数、荣誉总 数、团队业绩总数、电大系统课题项目数、服务社会总数、近五年教学业绩 等。实际用于预测的自变量与因变量如图 2 所示, 目标变量即是否通过评审 用 “1”表示通过, “0” 表示未通过。

(三) 决策树分析比较

通过对不同的自变量组合进行决策树统计分析, 结果略有不同, 如图 3 所示。但权重最高的变量始终相同, 都非常明显地显示出 “代表作鉴定” 对 最终结果的影响贡献度相对较高。当代表作评审得分为 8 分时, 即两项代表

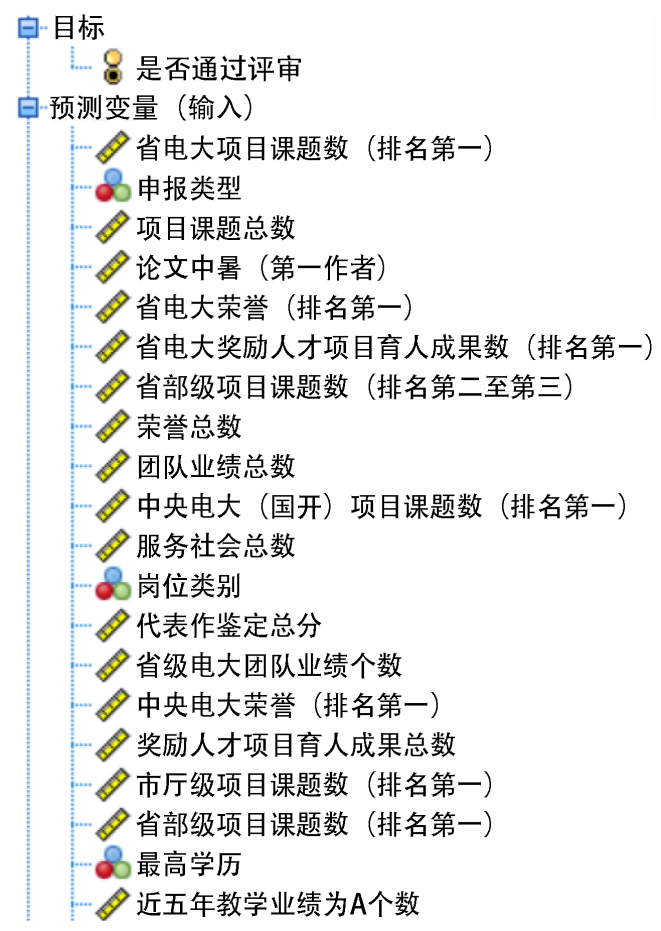

图 2. 预测自变量与目标变量
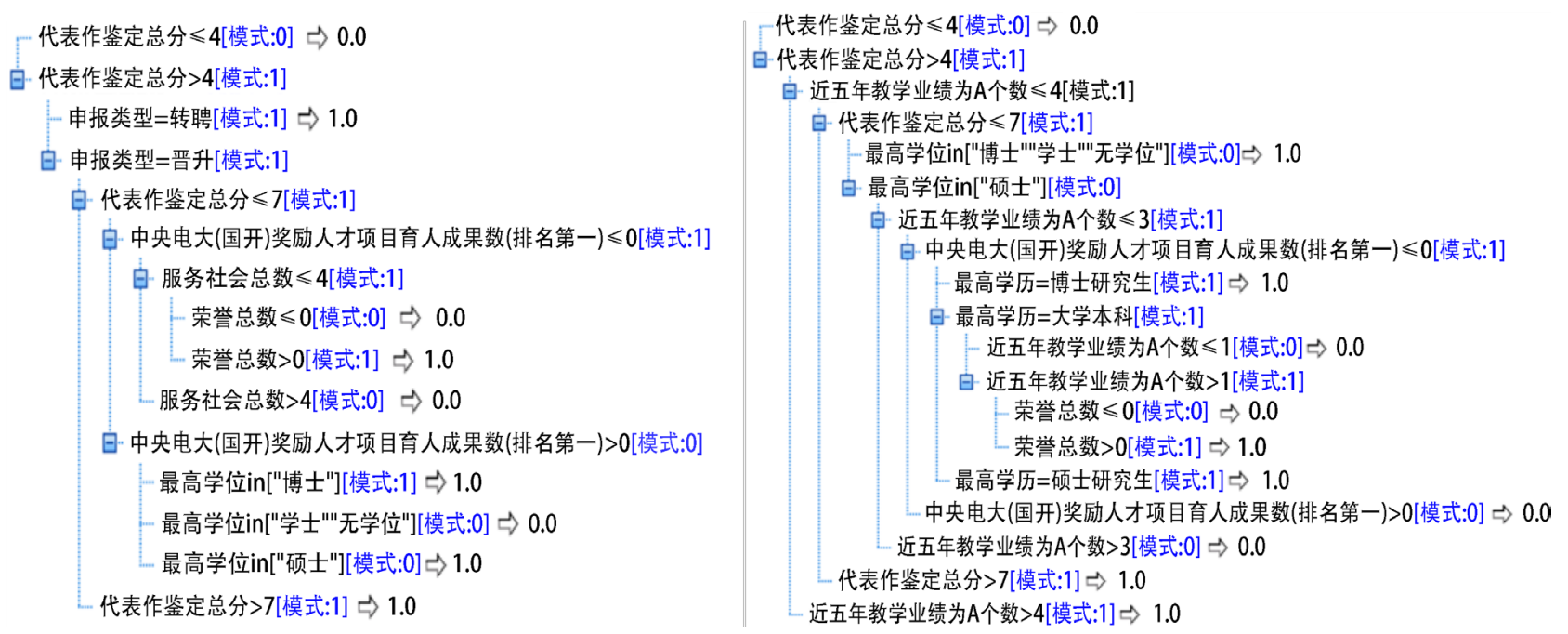

图 3. 决策树分析目录结构图 
作评审皆为 “A”, 职称评审通过率较高。如果代表作评审得分小于或等于 7 分时, 则教学业绩、学位及人才项目等都不同程度地影响评审结果。评审代 表作在各高校都几乎是评审指标中定位较高的条件之一, 这与评审代表作评 审过程及其特点有很大的关系。还有一个比较明显的特征, 在申报类型中, 当代表作评审得分大于 4 分时, “转聘” 的通过率较高。仔细比较 “转聘” 与 “晋升” 两类教师的其它属性, 发现 “转聘” 的各项指标并没有显著高于 “晋升”。因此, 可以看出造成这种结果的主要原因还是人为因素居多。从 决策树分层目录还可看出, 教师的教学业绩也排在了目录的较前端, 这与参 与评审类型多数为 “教学为主型” 有一定关系。

(四) 神经网络分析结果

为了进一步分析并建构职称评审预测模型, 本研究选取 SPSS Modeler 神 经网络模型建构功能中的多层感知器(MLP, Multilayer Perception)进行模型建 构与分析。多层感知器是一种前馈人工神经网络模型, 其将输入的多个数据 集映射到单一的输出的数据集上。多层感知器可以实现非线性判别式, 如果 用于回归, 可以逼近输入的非线性函数。同时, MLP 还可以用于 “普适近似”, 即具有连续输入和输出的任何函数都可以用 MLP 近似, 具有一个隐藏层的 MLP 可以学习输入的任意非线性函数。

在参数设定时指定过度拟合防止集合的记录的百分比为 $30 \%$, 分类目标 的默认合并规则为 “投票” 方式, 连续目标的默认合并规则选择 “均值” , 用于 boosting 和 bagging 的组件模型数量默认为 10。Bagging 是一种集成方法, 有助于降低方差, Boosting 提供了预测模块的连续学习功能。在开始训练时, Boosting 首先对原始数据集进行分类, 并给每个观测给予同样的权重。如果 第一个学习模块错误预测了类, 那么将会赋予错误分类观测较高的权重。由 此反复迭代, 不断添加分类学习模块, 直到达到模型数量或者某个准确度。

Boosting 有比 Bagging 更好的预测精准度, 但它有时也会过度拟合训练数据, 因此在设定它们的值时需要综合考虑。同时, 选择指定最大训练时间作为本 模型停止规则。

从运行结果汇总结构图如图 4、图 5 所示, 模型预测的准确度达 $84.9 \%$, 准确度较高。

如图 6 所示, 神经网络的隐藏层节点为 10 个, 输出层节点为 1 。结合图 5 和图 6 可以看出, 代表作鉴定、人才培养项目、项目课题总数、市厅级荣 誉、社会总数、团队业绩、论文总数(第一作者)、申报类型等指标对评审结果 的贡献度较大, 权重较高, 其中代表作鉴定尤其明显。通过预测结果导出表,

\section{是否通过评审的分类}

总体百分比校正 $=84.9 \%$

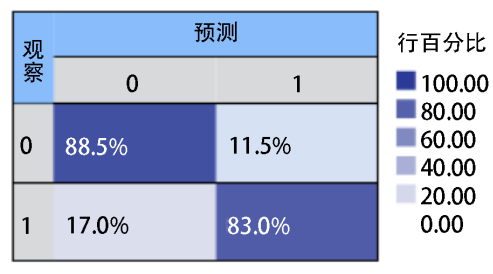

图 4. 综合预测变量指标重要性图 
预测变量重要性

目标:是否通过评审

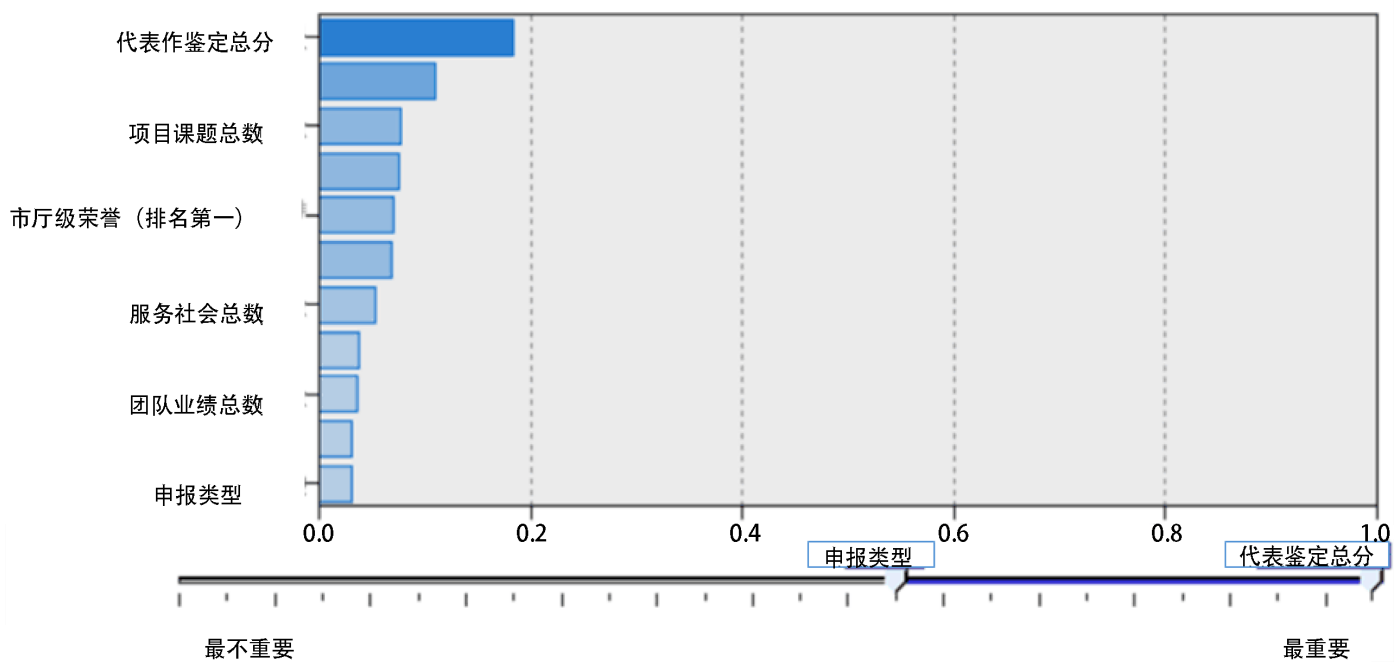

图 5. 指标重要性预测排行图

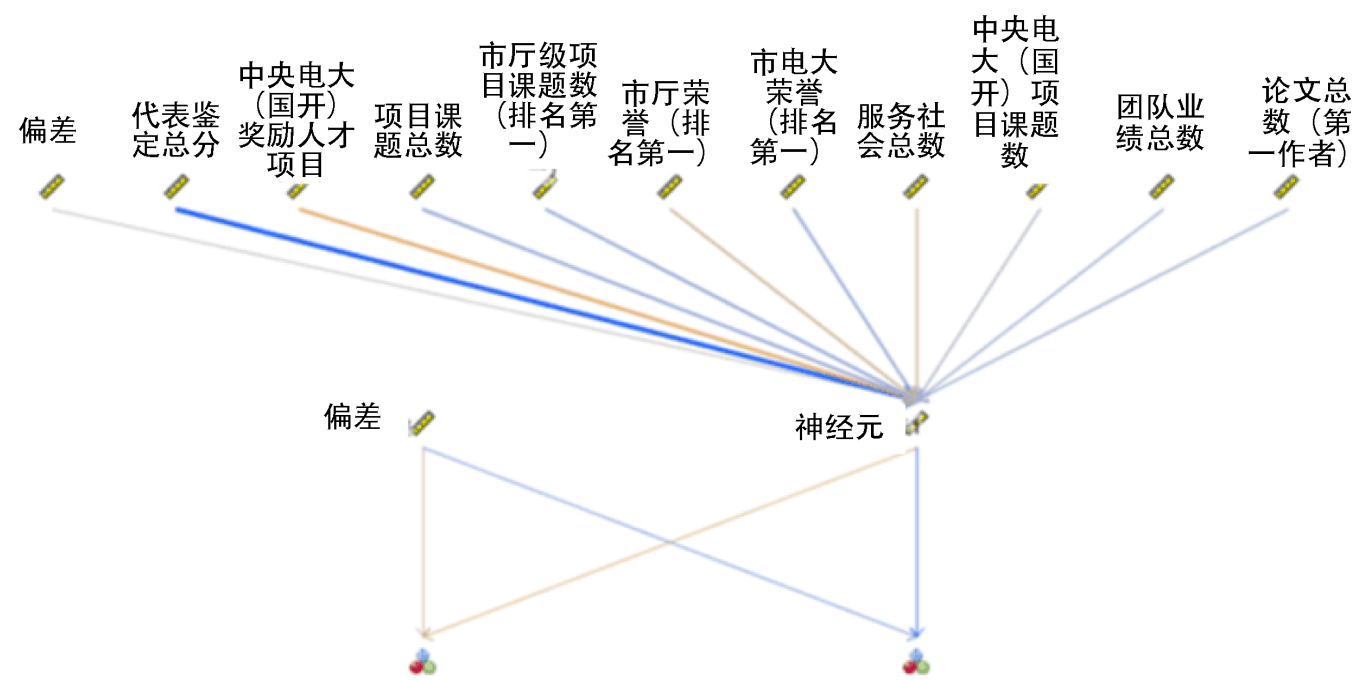

是否通过

评审 $=0$

是否通过

评审 $=1$

论文总数（第一作者）

代表作鉴定成分

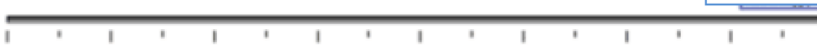

最不重要

最重要

图 6. 基于 MLP 的职称评审预测模型网络图

可以清楚看到实际通过评审、预测通过评审和预测正确率打分情况。如表 3 所示。表中第一栏显示的是实际的评审结果, 第二栏显示的是模型预测结果, 第三栏显示对输出结果预测的正确率。

由预测分析结果中各变量指标值可以看出, 模型的预测效果较好, 各项指 标权重及排行基本在预期范围内。但结合前述指标体系的建设, 也存在比较明 显的问题, 即多数指标并未进入实际的预测流程。其原因是数据缺失量大, 多 
表 3. 预测结果导出表(部分)

\begin{tabular}{ccc}
\hline 是否通过评审 & $\$ \mathrm{~N}$ 是否通过评审 & \$NC 是否通过评审 \\
\hline 0.000 & 0.000 & 0.792 \\
0.000 & 0.000 & 0.711 \\
1.000 & 0.000 & 0.729 \\
1.000 & 1.000 & 0.966 \\
0.000 & 0.000 & 0.717 \\
1.000 & 1.000 & 0.941 \\
0.000 & 0.000 & 0.690 \\
1.000 & 1.000 & 0.954 \\
1.000 & 1.000 & 0.966 \\
1.000 & 1.000 & 0.966 \\
\hline
\end{tabular}

数指标甚至是空白。根据目前对人才培养的定位和需求, 可以看出, 教师素质 与能力的提升空间还是非常大的, 这也对师资队伍建设提出了新的更高要求。

\section{4. 分析与建议}

(一) 问题分析

综合上述预测结果可以看到, 通过建立开放大学系统教师职称评审预测 模型, 可以集中解决促进职称评审量化与评审指标规范化问题, 揭示评审指 标的合理性, 对教师的职称评审起到部分引导作用, 对评委的评审过程也可 起到方向性的指导作用。

但当前职称评审过程中还存在一些尚需改进的问题:

1) 变量权重分配不平衡。决策树和神经网络模型的结果非常明显地突出 了 “代表作” 的权重, 远高于其它所有指标。这虽然与代表作的特点有一定 关系, 但也存在一定的人为主观因素。为避免过度抬高部分指标的权重, 导 致其它指标失去应有的贡献。在职称申报过程中可以将部分指标作为门槛条 件，以避免出现有些指标形同虚设的状况。

2) 缺乏明确的指标评定标准。对指标的评定应有更明确的规范与标准, 有些无法定量的指标需要进行合理引导。比如, 从公平以及人才队伍建设角 度出发, “转聘” 和 “晋升” 应该同等对待。非教师系列职称人员如果要 “转 聘” 到教师系列职称，则对其教学科研的要求应该与 “晋升” 教师系列职称 要求相同, 而不能考虑太多的其他因素。

3) 教学业绩指标不突出。申报教学为主型职称晋升的老师, 应该将其教 学业绩作为评审的重要指标。但从评审预测模型可以发现, 浙江广播电视大 学系统在近两年的职称评审过程中，除了部分硬性指标，如从事本职工作年 限、学位学历要求等基本要求外, 还是以科研成果为主。虽然从决策树可以 看出, 评审中教学业绩排在第三位, 但权重远低于前两项。作为教学为主型 的教师，突出教学业绩还是有很大的必要性。

4) 职称评审指标体系有待进一步完善。该指标体系的建立是在基于前两 年的职称评审基础上制定，并结合 2014、2015 两年的职称评审数据加以测试。 由于学校内涵建设不断加强, 人才队伍及教师素质也相应越来越高。所以, 
职称评审指标体系也应在实践中不断修订完善。

评审指标体系及评审预测模型等都是评审标准体系确立的重要因素和参 考。目前, 全国各高校的职称评审正逐步走向量化, 但在实际操作过程中, 由于种种原因, 很少完全实现量化评审。其主要原因是评审指标体系的建立 需要一个长期的过程, 不能一蹴而就。另外体系和模型建构及应用也是个动 态的过程, 需要不断调整完善, 短期内完全依靠指标体系和模型也是不合理 的。一个好的职称评价体系和预测模型可以在评审过程中起到很好的参考作 用, 并对人才培养方向及培养方案的制定起到引导性作用。

(二) 相关建议

根据浙江省和中央的精神, 结合广播电视大学当前的转型与定位需求, 我们还需要从以下四个方面优化职称评审量化指标, 面向开放大学蓝图, 设 计具备合理的有引导方向的职称评审预测模型, 建设完善的职称评审制度, 并在此基础上建立相应科学的指标评审体系, 合理量化职称评审指标。

1) 完善支撑评价标准。职称评定标准考虑了教学与科研、学历与能力等 诸多关系, 建立均衡合理的指标权重, 科研成果的量化指标作为基础权重指 标同时, 将工作业绩与科研并重。改变职称评审标准的论文导向, 将工作业 绩也作为重要的指标评审依据, 突出品德、能力、业绩导向等实践环节。完 善教师的工作业绩、科研数据的记录和存储, 并在制定评审标准及评审指标 量化时体现出来, 全面客观评价教师的工作业绩和综合素质, 凸显职称的评 价、激励作用, 同时对教师职业生涯发展也起到了指导作用。

2) 健全职称制度体系。开放大学的类型定位及办学特色决定, 其师资构 成需要多样化, 而实际发展配比不均衡。合理的职称评审标准与流程管理机 制是集聚人才的核心, 因此, 需要依托国家政策, 紧密结合开放大学师资队 伍建设需求, 依据人才培养、科学研究、社会服务的三大职能设计并细化职 称制度指标, 打通人才的分类管理, 制定出更为灵活和柔性的开放大学系统 特色与定位的职称评审制度, 赋予更多的灵活性和多样性, 改进职称管理服 务方式。

3) 创新职称评价机制。职称制度是一个系统工程, 改革的关键在于以职 业分类为基础, 尊重不同岗位、不同层级专业技术人员的职业特点和成长规 律, 科学分解、系统归类、量化评价, 根据社会经济、文化、教育的发展变 化及时调整、修正职称指标体系的评价因素, 既要保持政策的连续性和稳定 性, 又要突出动态、适应性的量化评价机制特征。

4) 促进开大人才培养。开放大学是远程教育办学系统, 应充分考虑各级 开放大学的建设发展需求, 增强开放大学系统师资及办学力量。在设计职称 制度指标时, 具有考虑评审因素多, 因素间相关性模糊、不确定等特质, 应 细化模块及细则, 建立多层次指标, 科学评估, 向基层和一线工作的专业技 术人才、急需紧缺的特殊人才倾斜, 提高人才在开放大学系统内部的开放性 和流动性, 激活系统的办学活力, 加快师资对现阶段社会经济发展需求的适 应性。

\section{5. 结语}

科技强国, 人才兴国。教育是社会发展的根本大计, 人才则是我国由人 
力资源大国向强国转变的重要因素。高校是创新的主力军, 聚集及培养国家 人才的睬化器, 在发展社会经济中起到了中坚力量, 而专业技术人才正是高 校人力资源的核心。因此, 对高教专业技术人才的评价方式要体现客观、公 正和科学的精神, 让他们有更多的时间和精力投入到专业技术工作上去; 让 在专业技术工作中做出更大贡献的人产生获得感和成就感。这些实际举措为 我国的人才建设和长远发展造就了良好的改革环境, 打下了坚实的制度基础。

高校教师职称制度历经三十年的探索, 各高校在国家政策引导下积极探 索实践。当前, 在广播电视大学系统积极服务于国家终身教育体系构建, 建 设开放大学的战略转型进程中, 师资队伍建设是一个非常重要的内容, 也需 要一个不断探索和实践的过程。合理应用职称评审量化思路和预测模型, 科 学把握人才成长和发展趋势, 进一步做好职称评审工作, 为教师专业技术成 长提供更为科学、合理的评价制度, 促进教师为学校事业改革和发展做出更 大的贡献。

\section{References}

[1] 葛跃. 高校教师职称评定的几点思考 [J]. 科技视界, 2014(6): 42.

[2] 秦远建, 余兴龙. 借鉴胜任力模型理论完善职称评审指标体系 [J]. 领导科学, 2011(26): 46-47.

[3] 1985 中共中央关于教育体制改革的决定 [EB/OL]. http://learning.sohu.com/20150528/n414011980.shtml, 2016-09-08.

[4] 中共中央印发《关于深化人才发展体制机制改革的意见》[N]. 光明日报, 2016-03-22(01).

[5] 中共浙江省委浙江省人民政府《关于深化人才发展体制机制改革 支持人才创业 创新的意见》 $[\mathrm{EB} / \mathrm{OL}]$.

http://zjnews.zjol.com.cn/zjnews/zjxw/201607/t20160712_1722488.shtml, 2016-07-12.

[6] 关于深化职称制度改革的意见[EB/OL]. http://baike.baidu.com/link?url=tILCs1Sn2-UjUMvBRh3yPWaHJ3iP2MDoGz jn8IT QW8D6uh2issbk1VTCg3JD BIcUf1gAii3c5rKguPuQHeoJQjtfkojV9 D1B7mkeKfa C6EM-JZr5 K0mxDS7xDbVaeo9dUKJ7s0MQF9uVFRv0MWl3yw5EVhttQ-ONk97 uR91F 1x2CdkdgEMdHsViMom69L3a8x1uPnweKWr7S3r5zZNI5uZzpkhpHHRQ-r CsajC, 2016-12-19.

[7] 赵晓芳. 基于胜任力模型的高职教师职称评定体系构建 [J]. 教育理论与实践, 2016(36): 26-28.

[8] 郑柏松. 系统论视角下高职教师职称评审体系构建探讨 [J]. 职业时空, 2015(5): $3-5$.

[9] 刘玉斌, 白雪云. 专业技术职称评审模型设计 [J]. 山东省农业管理干部学院学 报, 2000(3): 54-55.

[10] 安璐, 王欢, 黄朝君. 基于 BP 和 GRNN 模型的高校教师职称评审预测 [J]. 中国 管理信息化, 2015, 18(3): 183-184.

[11] 王正东. 蝶变与涅槃: 开放大学建设进程中广播电视大学的转型 $[\mathrm{J}$. 远程教育杂 志, 2016(3): 63-68.

[12] 教育部关于办好开放大学的意见[EB/OL]. http://www.moe.edu.cn/srcsite/A07/moe_726/201602/t20160202_229322.html, 2016-10-09

[13] 李翠芬. 基于数学模型的教师职称结构均衡发展研究 [J]. 高等农业教育, 2014(2): 47-50.

[14] 陈川杨. 高校职称评聘的综合评价模型[J]. 统计与决策, 2006(2): 137-139. 
[15] 裴纪平. 江苏高校教师职称评审代表作同行专家鉴定工作的思考 [J]. 当代职业 教育, 2014(9): 83-86.

[16] 徐璟. 高校人力资源管理的导向性研究——职称量化测评对科研绩效影响的实 证分析[J]. 黑龙江高教研究, 2009(5): 62-65.

Submit or recommend next manuscript to OALib Journal and we will provide best service for you:

- Publication frequency: Monthly

- 9 subject areas of science, technology and medicine

- Fair and rigorous peer-review system

- Fast publication process

- Article promotion in various social networking sites (LinkedIn, Facebook, Twitter, etc.)

- Maximum dissemination of your research work

Submit Your Paper Online: Click Here to Submit

Or Contact service@oalib.com 